\title{
ANÁLISE DOS CONTEÚDOS E SABERES PRESENTES NO COMPONENTE CURRICULAR EDUCAÇÃO FÍSICA NO REFERENCIAL CURRICULAR LIÇÕES DO RIO GRANDE
}

\author{
ANALYSIS OF THE CONTENTES AND KNOWLEDGE PRESENTE IN THE CURRICULAR \\ COMPONENTE PHYSICAL EDUCATION IN THE CURRICULAR REFERENCE LIÇÕES DO RIO \\ GRANDE
}

\section{ANALISIS DE LOS CONTENIDOS Y SABERES PRESENTES EN EL COMPONENTE CURRICULAR EDUCACIÓN FÍSICA EN LO REFERENCIAL CURRICULAR LIÇÕES DO RIO GRANDE}

\author{
Bruno de Oliveira e Silva ${ }^{1}$ \\ Leonardo Trápaga Abib² \\ José Geraldo Soares Damico ${ }^{3}$
}

Resumo: O objetivo do presente artigo é analisar os modos pelos quais os conteúdos do componente curricular Educação Física encontram-se dispostos e organizados no Referencial Curricular Lições do Rio Grande (LRG). Os materiais empíricos foram os documentos do LRG e entrevistas semiestruturadas com os organizadores do fascículo da Educação Física. Os dados foram analisados sob a perspectiva dos estudos pós-estruturalistas. No primeiro eixo de discussão são abordadas questões referentes à organização do referencial curricular enquanto no segundo são discutidos os conteúdos e saberes sobre Educação Física. Nas LRG o currículo por competências encontra-se articulado à permanência do currículo disciplinar. O LRG utiliza-se de uma discursividade acerca do saber da cultura corporal de movimento para justificar o privilégio do esporte enquanto conteúdo em detrimento dos demais. A forma proposta de sequência e divisão dos saberes da Educação Física acaba por deixar pouco espaço para momentos de criação de professores e alunos.

Palavras-chave: Currículo. Educação Física. Escola.

\begin{abstract}
The objective of this article is to analyze the ways in which the contents of the Physical Education curricular component are arranged and organized in the Curriculum Reference Lições do Rio Grande (LRG). The empirical materials were LRG documents and semi-structured interviews with the organizers of the Physical Education issue. The data were analyzed from the perspective of poststructuralist studies. In the first axis of discussion, issues related to the organization of the curricular framework are addressed, while in the second, the contents and knowledge about Physical
\end{abstract}

\footnotetext{
${ }^{1}$ Universidade Federal do Espírito Santo. Vitória, Espírito Santo, Brasil.

${ }^{2}$ Universidade Federal do Espírito Santo. Vitória, Espírito Santo, Brasil.

${ }^{3}$ Universidade Federal do Rio Grande do Sul. Porto Alegre, Rio Grande do Sul, Brasil.
} 
Education are discussed. In the LRG, the competency curriculum is linked to the permanence of the disciplinary curriculum. The LRG uses a discourse on the knowledge of body culture of movement to justify the privilege of sport as content to the detriment of others. The proposed form of sequence and division of knowledge of Physical Education leaves little space for moments of creation of teachers and students.

Keywords: Curriculum. Physical Education. School.

Resumen: El propósito de este artículo es analizar las formas en que los contenidos del componente curricular de Educación Física están ordenados y organizados en el Curriculum Reference Lições do Rio Grande (LRG). Los materiales empíricos fueron documentos LRG y entrevistas semiestructuradas con los organizadores de la edición de Educación Física. Los datos se analizaron desde la perspectiva de los estudios postestructuralistas. En el primer eje de discusión se abordan temas relacionados con la organización del marco curricular, mientras que en el segundo se discuten los contenidos y conocimientos sobre Educación Física. En el LRG, el currículo de competencias está vinculado a la permanencia del currículo disciplinar. EI LRG utiliza un discurso sobre el conocimiento de la cultura corporal del movimiento para justificar el privilegio del deporte como contenido en detrimento de los demás. La forma propuesta de secuenciación y división del conocimiento de la Educación Física deja poco espacio para momentos de creación de profesores y alumnos.

Palabras clave: Currículo. Educación Física. Escuela.

\section{CONSIDERAÇÃO INICIAIS}

O processo de escolarização é elemento importante para pensar a respeito da educação do corpo e das técnicas e dispositivos mobilizadas ao longo do tempo para disciplinar e regular os sujeitos. Neste caso entendemos que essas técnicas se constituem, imersas em um campo de relações de poder e saber, se materializam na escola por meio de normativas, organização dos espaços físicos, conteúdos, componentes curriculares, entre outros. Para o presente texto nos interessa a discussão acerca dos processos de elaboração e implementação de diretrizes curriculares na escola, tendo em vista o papel central que essas possuem na formação dos sujeitos.

A garantia da formação básica comum para os cidadãos é regulamentada especialmente a partir da Lei de Diretrizes e Bases da Educação Nacional (LDB) e de uma série de documentos produzidos no Brasil. Destacam-se entre eles os Parâmetros Curriculares Nacionais do Ensino Fundamental e do Ensino Médio (PCNs), as Diretrizes Curriculares Nacionais e, mais recentemente, a Base Nacional Curricular Comum (BNCC), as quais, apesar de terem em seus conteúdos algumas diferenças importantes quanto à estrutura e ao processo de construção, compartilham princípios comuns.

Com a publicação da LDB (BRASIL, 1996) e dos PCNs (BRASIL, 1997), diversos estados e municípios brasileiros passaram a construir e implementar seus referenciais curriculares, buscando aliar as prerrogativas nacionais a aspectos regionais. Nesse sentido, as produções e as propostas 
sobre as questões curriculares e a formação do professor vem acontecendo de múltiplas formas, com o objetivo de dar conta dos contextos e das particularidades locais ou regionais.

O Rio Grande do Sul foi um dos estados que nos anos 2000 aderiu ao modelo de produção e execução de um referencial regional. O Referencial Curricular do Rio Grande do Sul - também conhecido como Lições do Rio Grande (LRG) - foi um documento produzido pela Secretaria de Estado da Educação do Rio Grande do Sul (Seduc/RS) em conjunto com professores e especialistas convidados pela mesma (RIO GRANDE DO SUL, 2009).

Um dos componentes curriculares que foi atendido pelos Referenciais foi a Educação Física. No Referencial Curricular do Rio Grande do Sul, em especial nos volumes que versam acerca do componente curricular Educação Física, a relação ensino e aprendizagem é estabelecida pelo trato com as práticas e os saberes da cultura corporal de movimento. Estabelece-se, assim, uma maneira de se ensinar e aprender no interior da disciplina educação física nas escolas estaduais do Rio Grande do Sul.

No campo acadêmico dessa área, tem crescido o número de pesquisas e publicações a respeito de currículo e da construção de propostas curriculares para o ensino na educação básica (LIMA; ALMEIDA, 2019; OLIVEIRA; NEIRA, 2018; RODRIGUES; DARIDO, 2011; SOUZA JUNIOR et al., 2015). Nesse sentido, nosso objetivo para o presente artigo está em analisar os modos pelos quais os conteúdos do componente curricular Educação física encontram-se dispostos e organizados nas LRG.

\section{PERCURSO METODOLÓGICO}

Para a realização desta investigação ${ }^{4}$, mobilizamos um conjunto de articulações teóricas e metodológicas vinculadas ao campo dos estudos pós-estruturalistas em educação. Dentre essas, valemo-nos nos estudos culturais (HALL, 2002), das teorias do currículo (CORAZZA, 2001; SILVA, 2011) e de teorizações foucaultianas (FOUCAULT, 2008; 1993), de modo a ir ao encontro de uma atitude crítica. Os currículos necessitam de cuidados especiais em sua configuração como objeto, exigindo assim a identificação dos poderes e saberes que seus enunciados ativam e colocam em circulação. Para tanto, buscamos nos aproximar da instabilidade de uma análise ímpar, que caracteriza um dado momento histórico. Na ânsia de entender esse artefato pedagógico em

\footnotetext{
${ }^{4}$ O presente artigo é fruto da dissertação de mestrado de Silva (2014).
} 
operação, nós o analisamos da seguinte maneira: o que fez com que esse referencial curricular fosse construído de um modo e não de outro?

Por entender que representar é produzir significados, tomamos o RC Lições do Rio Grande enquanto texto produzido por uma linguagem que é resultante das relações de poder entre diferentes grupos que disputam o direito de proferir a fala a respeito do que ocorre no espaço escolar. É nesses termos que o currículo pode ser também entendido como uma linguagem, uma prática social, discursiva e não discursiva, que se corporifica em instituições, regulamentos, programas, valores, modos de ser sujeito (CORAZZA, 2001).

Metodologicamente operamos com os aportes da análise cultural, com a pretensão de desconstruir algumas naturalizações (SILVA, 2011) nos discursos sobre o componente curricular Educação física presentes nas LRG. A análise cultural (HALL, 2002) visa à pluralidade de significações, mostrando como ocorrem as invenções das verdades, apontando as rasuras, as disputas, que no âmbito dos discursos produzem "identidades e subjetividades, no contexto das relações de poder" (TRINDADE, 2007, p. 43).

Esta atitude analítica de pesquisa, pautada nos estudos culturais, se consolida nas dinâmicas de discursividade, onde o Referencial Curricular do Rio Grande do Sul, se estabelece enquanto um artefato pedagógico que versa sobre a Educação física escolar, veiculando e representando "formas pelas quais diferentes práticas sociais [...] constroem os diferentes objetos sociais que se configuram" (ALVARENGA, 2006, p. 40), a partir de determinadas condições e possibilidades de existência.

O principal material empírico da presente pesquisa foram os documentos que compõem e formam as Lições do Rio Grande. Estes estão organizados a partir de quatro grandes áreas do conhecimento, já preestabelecidas no Referencial Curricular da Secretaria de Estado da Educação, que são: Linguagens (onde se encontra o componente curricular Educação Física); Matemática; Ciências da Natureza; e Ciências Humanas. Cada um desses volumes representa a construção conjunta de um grupo de componentes, conteúdos e elementos pedagógicos, que buscam se aproximar das discussões teórico-metodológicas a serem desenvolvidas no ambiente escolar do Ensino Fundamental e Médio das escolas estaduais do Rio Grande do Sul.

Como parte do caminho investigativo que venho trilhando nesta pesquisa, optamos, como mais um elemento para análise, realizar entrevistas com os autores do volume Educação física (Referencial Curricular, Caderno do professor e Caderno do aluno) das Lições do Rio Grande. Após a elaboração do roteiro e envio prévio aos entrevistados, foram marcadas as entrevistas com os 
professores Alex Branco Fraga e Fernando González. Justificamos essa escolha pelo fato de esses terem sido os professores/pesquisadores da área da Educação Física que ficaram responsáveis pela construção e finalização do documento.

As entrevistas foram transformadas em documento escrito, sendo transcritas, inicialmente, de forma literal, seguida pela conferência de fidelidade e pela pesquisa, que é o processo de ouvir novamente a gravação, conferindo as falas e acrescentando notas de rodapé, citações e termos pouco usuais e/ou regionais, que identificam e fornecem dados mais precisos. A partir desses documentos foi realizado o copidesque, de modo a garantir o conteúdo expresso pelos entrevistados. Após a realização de todos esses procedimentos - transcrição, conferências de fidelidade, pesquisa e copidesque -, a entrevista retornou para os entrevistados, para que eles realizassem a leitura final do texto, podendo ainda indicar possíveis modificações.

A partir dos dados produzidos nas análises dos documentos e nas entrevistas, estruturamos nossa escrita para este texto em dois eixos de discussão, em que no primeiro são abordadas questões referentes à organização do referencial curricular e no segundo são discutidos os conteúdos e saberes sobre Educação física que emergem dos materiais do LRG.

\section{AS ORIENTAÇÕES DAS LIÇÕES DO RIO GRANDE E SEUS IMPACTOS NA FORMULAÇÃO DE DIRETRIZES CURRICULARES ESPECÍFICAS}

Para a análise do presente eixo partimos do seguinte argumento: os referenciais curriculares LRG, como um todo, firmaram uma aliança com formas muito atuais das democracias liberais, introduzindo dispositivos de controle e regulação advindos da lógica empresarial e do mercado (AMARAL, 2010). Tal argumentação nos provoca a estranhar uma série de discursos que tentam 'dourar a pílula' e simplesmente tratar dos materiais como um objeto puro, neutro, científico.

Uma noção importante e que ajuda a rasurar a posição de que "quem faz o currículo é o aluno junto com o professor" (GONZALEZ, 2013, p. 26) se dá a partir dos estudos culturais, que entendem que o conhecimento e o currículo são objetos constantemente envolvidos de interpretação e disputa, em que diferentes grupos tentam obter hegemonia. Ou seja, ainda que González (2013) tenha razão, em parte, seria preciso completar essa sentença: desse modo, temos que o currículo "[...] é aquilo que nós, professores/as e estudantes fazemos com as coisas, mas é também aquilo que as coisas que fazemos fazem a nós. O currículo tem de ser visto em suas ações e em seus efeitos" (SILVA, 2002, p. 194). 
Por seu caráter de construção social as Lições do Rio Grande apresentam uma determinada estrutura, organização, conhecimentos, conteúdos, itens, autores, experts e não outros nomes, outras formas de estruturar ou até mesmo não estruturar um currículo. Por isso, é que o currículo não está restrito ao professor e ao aluno, ele não é um reflexo da natureza ou da realidade, mas o resultado de um processo de criação e de interpretação social. É possível ainda dizer que o artefato pedagógico é um artefato cultural, ou seja, ele é produzido no âmbito da cultura, logo, imerso em relações de poder e disputa por imposições de significados.

Ao dirigirmos nossos olhares para as formulações da Educação física, chamamos atenção para uma série de grupos e perspectivas teóricas que vêm há muito tempo buscando tomar para si um possível protagonismo na sistematização dos conteúdos da Educação física escolar. Trata-se frequentemente de uma disputa por hegemonia em termos de definir o que deve ser ensinado, como deve ser ensinado e o que deve ser apreendido.

É nessa medida que o 'artefato' funciona como um instrumento, um documento produzido por um grupo de experts, que trazem em si discursos e representações do que é ser iniciado, 'alfabetizado' na chamada cultura corporal de movimento, a partir dos efeitos que se imagina que o ingresso nessa 'cultura' possa promover:

[...] os artefatos culturais/pedagógicos podem governar os sujeitos através da delimitação e normatização de condutas. Assim, os discursos dos artefatos culturais são resultados de um conjunto de práticas que os antecede e que neles se atualiza e se multiplica. A governamentalidade pode ser entendida como a conduta da conduta (RENOVATO, 2009, p. 1600-1601).

As Lições do Rio Grande passam a ser consideradas um artefato pedagógico, ao passo que se produzem como um instrumento que determina, delimita e normaliza a forma a qual se devem dar as relações na disciplina Educação física no ambiente escolar. Um exemplo disso é quando o documento se pronuncia, dizendo:

O Referencial Curricular da Educação Física do Estado do Rio Grande do Sul sistematiza um conjunto de competências e conteúdos que esta matéria de ensino se encarrega de tratar. É um esforço de explicitação dos saberes considerados fundamentais neste campo, organizados com a intenção de auxiliar no planejamento e na implantação de propostas de ensino que favoreçam o processo de apropriação, problematização e uso criativo por parte dos alunos do que ali está sugerido. O Referencial é um ponto de apoio, e não um texto substituto, ao processo de elaboração dos planos de estudo de cada instituição [...]. Este Referencial deve ser entendido como um movimento preliminar de organização de saberes 
dentro de uma disciplina com pouca tradição na elaboração de projetos curriculares. Este documento foi concebido para funcionar como um guia de estudo e não como um manual de instruções, portanto, não é o fim da linha, e sim o ponto de partida de uma série de discussões sobre o que deve ser ensinado em Educação Física na escola (GONZÁLEZ; FRGA, 2009a, p. 114).

Nessa relação, os experts/consultores são detentores de um determinado tipo de saber, já definido e desenvolvido no documento Lições do Rio Grande. Apoiando-nos nas teorizações de Michel Foucault (2008), torna-se difícil não estabelecer uma relação entre a proposta de sistematização dos elementos da cultura corporal de movimento, descritos nas Lições do Rio Grande, com uma noção de governo das condutas dos sujeitos que se encontra imbricada nessa proposta de prática pedagógica estabelecida pela disciplina Educação Física.

O governo do social e do educável torna não só internamente manobrável dentro de seu aparelho político, como também a distância: através do cálculo sobre a conduta de cada indivíduo. É nessa medida que um tipo de autoridade, sustentada num dado conhecimento, neutralidade e eficácia social, funciona com uma expertise com autoridade moral e técnica para falar pelo governo formal (CORAZZA, 2002).

É interessante perceber, nos excertos acima, como há todo um discurso de respeito, de movimento preliminar, de auxílio na organização dos saberes, como guia de estudos, não como manual, como ponto de partida, ponto de apoio e não um substituto para planos de ensino etc. Tal cuidado no uso de determinadas palavras que posicionam os referenciais da Educação Física como coadjuvantes vai na direção contrária quando, no início do excerto, afirma uma posição firme que esses são os elementos que devem ser tratados e, no final do excerto, que "devem ser ensinados". Essas construções discursivas são sintonizadas com a racionalidade contemporânea de governamento, ou seja, através de uma função-lugar, estrutura modos calculados de ação sobre as forças, atividades e relações de cada indivíduo e da população para atingir determinados fins.

Outra operação que perpassa o texto das Lições do Rio Grande referente à Educação Física e, especificamente no excerto que estamos comentando, tem a ver com uma espécie de assepsia em relação ao objeto de conhecimento. Não há pessoas, indivíduos etc., apenas a cultura corporal de movimento. Alunos e professores são, desse modo, também objetiváveis, peças de uma engrenagem, ao mesmo tempo, parceiros voluntários de seu governo.

Coutinho e Sommer (2011), apoiados nas produções discursivas sobre a formação de professores, indicam que essas formulações acerca do currículo são importantes para destacar que, no âmbito das políticas educacionais brasileiras, existe uma espécie de simbiose, uma relação muito 
estreita entre estas várias ideias e perspectivas de se pensar o currículo e os sujeitos educados. Isso nos possibilita pensar que exista uma pluralidade nos diversos saberes que compõem o ensino de uma disciplina curricular no âmbito escolar. Acreditamos que a própria Educação Física esteja enviesada dessa retórica de múltiplos currículos, saberes e elementos discursivos, como no que se refere às discussões da utilização das competências a serem desenvolvidas:

Essa ideia tem merecido diversas críticas de setores sociais que veem a educação como uma forma de contribuir na formação do cidadão, e não como uma mera preparação para o mundo do trabalho. Portanto, as competências não podem se restringir àquelas voltadas ao bom desempenho em um emprego, elas também devem contemplar competências que possibilitam pensar e agir no mundo em busca de melhores condições de vida para todos em um sistema democrático [...]. Em consonância com a ideia anteriormente descrita, o conceito de competência também pode ser usado como operador da organização do currículo. No contexto brasileiro, durante as últimas décadas, os gestores de políticas educacionais geraram um conjunto de reformas que tiveram como eixo central a elaboração de documentos curriculares. Nesse movimento, foram instituídos, em diferentes níveis do sistema educacional nacional, parâmetros, diretrizes e processos de avaliação externa (ENEM, ENAD, SAEB), sustentados fundamentalmente no conceito de competência (GONZÁLEZ; FRGA, 2009a, p. 115).

Pontuaremos uma questão importante advinda do excerto supracitado: a tentativa de desvincular o material produzido de uma lógica neoliberal voltada para o mercado de trabalho e ao bom desempenho no emprego. Na sequência, propõem outro uso das competências para pensar e agir em busca de melhores condições de vida. Seria realmente possível desvincular uma lógica da outra? Ao se produzir um referencial curricular estadual na busca de educar e moralizar para o exercício de uma certa cidadania, não se estaria formando um trabalhador adaptado, conformado, flexível etc.? Na perspectiva da modernidade líquida, nos dizeres de Bauman, a cidadania da modernidade sólida sofre um abalo:

Recordando a famosa tríade de direitos de Thomas Marshall: os direitos econômicos agora estão fora das mãos do Estado, os direitos políticos que ele pode oferecer são estritamente limitados e circunscritos àquilo que Pierre Bourdieu batizou de pensée unique do livre mercado neoliberal plenamente desregulado, enquanto os direitos sociais são substituídos um a um pelo dever individual do cuidado consigo e de garantir a si mesmo vantagens sobre os demais (BAUMAN, 2005, p. 34).

Neste contexto, pode-se colocar sob suspeita o significado de cidadania construído na modernidade uma vez que boa parte de seus antigos conteúdos vem sendo crescentemente esvaziados e até mesmo as instituições estatais que davam suporte e credibilidade estão sendo 
desmanteladas. Para Tomaz Tadeu da Silva (1995), a nova direita sul americana que emerge nos anos 1990 vem colocando a educação e o currículo no centro de reestruturação da sociedade em critérios baseados no funcionamento do mercado, como, por exemplo, o conceito de competência:

O PSDB de alguma forma, ele tem alguma inspiração, eu entendo, uma reforma feita particularmente em Minas Gerais e em São Paulo. E de alguma forma eles trabalhavam com a ideia da competência, como um elemento muito interessante, assim... Mas de um elemento que deveria organizar o trabalho (GONZÁLEZ, 2013, p. 6).

A centralidade da competência na organização curricular nacional é apontada por certos setores educacionais como um modo de dar continuidade às teorias da eficiência social ou da pedagogia dos objetivos. Este tipo de análise vê todo e qualquer projeto curricular estruturado por competências como um documento marcadamente instrumental, comportamentalista e fragmentado, mais comprometido com a formação do capital humano do que com cidadãos capazes de se engajar no processo de democratização da sociedade (GONZÁLEZ; FRAGA, 2009a, p. 115).

Cabe examinar que os referenciais do RS, quando do seu processo de formulação, tinham uma clara linha político-ideológica, pautada tanto pelas experiências nacionais com os PCNs como com as experiências estaduais em São Paulo e Minas Gerais no começo dos anos 2000. Em todas essas ações, a lógica da racionalidade proposta era direcionada para a formação de um cidadão flexível, com capital humano para adequar-se ao mercado em constante mudança.

O currículo por competências em geral e este em particular não têm por objetivo o questionamento mais profundo das concepções de conhecimento dominantes. Ao contrário, ele contribui para favorecer processos de inserção social e de aceitação do modelo social vigente. Isso porque o princípio integrador situa-se no mundo produtivo: são integrados os saberes necessários para execução de atividades profissionais segundo as exigências de mercado.

Em números absolutos, entre gerais e específicas, são 17 competências a serem atingidas/construídas no componente curricular Educação Física. Antes de tecer uma investigação sobre as competências, vale a pena pensar na bipolaridade competência/incompetência. Não raras vezes, a secretária de Educação do Rio Grande do Sul no período da implementação das Lições do Rio Grande declarou que o problema principal da qualidade da educação era o seu professorado. Nas suas palavras ${ }^{5}$ :

\footnotetext{
${ }^{5}$ Esta fala foi retirada de palestra proferida pela professora Mariza Abreu, no ano de 2011, por ocasião do 3 o Seminário Líderes em Gestão Escolar, tendo como tema: Plano de carreira: como selecionar e manter os melhores professores em sua rede. Disponível em: http://www.youtube.com/watch?v=eAP7hmOHY7g. Acesso em: 8 jan. 2014.
} 
E todas aquelas questões [...] são mais ou menos a mesma do 'Todos pela Educação'. Currículo, autonomia com responsabilização, uso competente dos processos de avaliação. Eu, não é só porque eu fui professora, mas eu tenho plena consciência de que o nosso nó górdio é a questão do magistério. Enquanto a gente não resolver o problema do magistério, não adianta, não tem. Todo mundo que estuda educação diz que a qualidade de um sistema de educação é igual à qualidade de seus professores (ABREU, 2011, s/p).

Nas Lições do Rio Grande, a participação dos sujeitos que integram o cotidiano escolar obteve pouca materialidade no documento, haja vista que se produziram apenas algumas relações entre a construção do documento e esses sujeitos, em especial os professores e alunos da rede estadual de ensino do Rio Grande do Sul. Como se notou nas entrevistas realizadas, a participação de professores da rede se deu por ações isoladas.

Voltando aos ditos e não ditos, agora em relação entre si, pode-se notar que, basicamente, o que emerge nas Lições do Rio Grande sobre as questões relativas às identidades são alguns escassos ditos:

Cooperação, solidariedade, tolerância, liberdade, igualdade, pacifismo são temas que emergem nas aulas a todo instante, por isso; mesmo que possam ser abordados sob o ponto de vista conceitual, não cabe propor num Referencial Curricular a sistematização de uma sequência de saberes atitudinais a serem ensinados, e sim, delinear princípios gerais de desenvolvimento das aulas que primem pelo bem viver coletivo e, consequentemente, pelo bom relacionamento entre os alunos (GONZÁLEZ, FRAGA, 2009a, p. 116).

É reconhecida a importância e é pontuado que, por isso, os ditos “cooperação, solidariedade, tolerância, liberdade, igualdade, pacifismo são temas que emergem nas aulas a todo instante" (GONZÁLEZ; FRAGA, 2009a, p. 116) devido a isto os mesmos, não devem ser trabalhados ou desenvolvidos enquanto uma sistematização de conteúdos, já que estão presentes no princípio geral de todas as aulas. Tal afirmativa permite ver a lógica de ocultação das relações de governo de si e dos outros.

Sobre o não dito, há ainda pelo menos mais uma menção a fazer e que possui relação com a ausência absoluta das questões sobre identidades, que seriam centrais em um currículo que minimamente se propusesse a dialogar com outras perspectivas menos tradicionais, principalmente a partir de

[...] uma perspectiva que reconhece o descentramento da consciência e do sujeito, a instabilidade e provisoriedade das múltiplas posições em que são colocados pelos múltiplos e cambiantes discursos em que são constituídos, começa por questionar 
e interrogar esses discursos, desestabilizando-os em sua inclinação a fixá-los numa posição única que, afinal, se mostrará ilusória (SILVA, 1994, p. 249-250).

Assumir o caráter produtivo do currículo significa tomá-lo na dimensão de seus efeitos, ou seja, tomá-lo através de suas narrativas, seus discursos, que, de modo mais ou menos explícito, introjetam noções características sobre conhecimento, organização social e diferentes grupos sociais.

Faz-se necessário enfatizar que os objetivos de um currículo, na perspectiva trabalhada, não são meramente ornamentais ou estéticos, mas sua utilização está estreitamente ligada a relações de poder. Sendo assim, faz-se pertinente questionar sobre "[...] quais grupos sociais estão representados no conhecimento corporificado no currículo? De que forma eles são descritos? Quais são as ideias de gênero, de raça, de classe, apresentadas nos diferentes textos curriculares?” (SILVA,

2011, p. 194). É através de interrogações como essas que o currículo pode se tornar um território contestado, algo que os não ditos do currículo em questão nos mostram não ser sua opção políticoepistemológica.

\section{AMBIÇÃO DISCIPLINAR E LEGITIMAÇÃO DA EDUCAÇÃO FÍSICA ESCOLAR}

Nesta seção discutiremos a respeito dos dispositivos pedagógicos e das concepções de Educação Física, professores e alunos que se fazem presentes nos materiais analisados no Referencial Curricular do Rio Grande do Sul. Ao longo de sua trajetória no campo escolar, a Educação Física teve diversas transformações e proposições do que ensinar, ou de qual o conhecimento é necessário ensinar, tendo tido influência de diferentes referenciais teóricos e práticos, como os métodos ginásticos na primeira parte do século $X X$, a esportivização fortemente marcada pós anos 1960, a psicomotricidade, a saúde renovada e as correntes ligadas aos campos críticos, como, por exemplo, o Movimento Renovador e o Currículo Cultural (SOARES, 1994; BRACHT, 1999; NEIRA, 2011).

Boa parte das propostas pedagógicas no âmbito da Educação Física escolar é tributária de grupos que propunham e disputavam a hegemonia através da defesa da necessidade de que os conteúdos (currículos) fossem sistematizados. Esse fato se materializa na aprovação dos PCNs e da LDB, que, apesar de seu processo de tramitação ser eivado de tensões, resulta de um conjunto de diretrizes e marcos legais, propiciando ou sugerindo o que e como deve ser tratada essa disciplina no currículo formal das escolas e na prática pedagógica (FARENZENA, 2010). 
No caso das LRG, ganha destaque no documento e na fala de seus autores o Movimento Renovador, que se constitui a partir do processo de 'repedagogização' da Educação Física no Brasil. Conceitos como cultura corporal, cultura de movimento e cultura corporal de movimento (CCM) se tornam conhecidos (CAPARROZ, 2005), tal qual defendem os organizadores da parte específica da Educação Física nas Lições do Rio Grande.

De certo modo, querendo ou não, de acordo ou não, todos nós que lidamos com a Educação Física escolar no âmbito acadêmico somos herdeiros do movimento renovador, porque foram os primeiros movimentos em torno de organização curricular que passaram a pensar a Educação Física como uma disciplina responsável pela cultura corporal de movimento, por meio das práticas corporais sistematizadas (FRAGA, 2013, p. 6).

Apesar de entender que o Movimento Renovador da Educação Física se constituiu ao longo dos anos como referência acadêmica no âmbito escolar, também é possível afirmar, discordando dos autores das Lições do Rio Grande, que em diversos espaços formativos vem sendo produzidas outras formas de se pensar a disciplina. Dentro da própria proposta do Movimento Renovador há cisões e divergências que aproximam e afastam os autores. Dessa forma, nas LRG o Movimento Renovador é uma 'opção', envolta de relações de poder e saber que produzem modos de viver e educar os corpos dos sujeitos alunos e professores.

Os Parâmetros Curriculares Nacionais têm como objeto de estudo para a Educação Física a CCM, mesmo objeto que os autores das LRG se apoiaram para justificar o que deve ser ensinado nesse componente curricular. Segundo os autores do volume das Lições do Rio Grande dedicado à Educação Física,

A gente procurou tratar no referencial do legado que nos foi deixado pelo Movimento Renovador, que é entender a disciplina da Educação Física escolar como uma disciplina de fato, que está articulada com as outras disciplinas em prol de uma educação que possa fazer com que os meninos e meninas se conectem com - mundo, desenvolvam uma capacidade crítica, dentro daquilo que cabe à Educação Física tratar, ou seja, as práticas corporais sistematizadas, essas representações sociais em torno delas, a relação que ela estabelece com o campo da saúde e com o campo do lazer (FRAGA, 2013, p. 6).

[...] fica claro que tornar os alunos fisicamente aptos não deve mais ser a principal finalidade dessa disciplina na escola, e sim levar os estudantes a experimentarem, conhecerem e apreciarem diferentes práticas corporais sistematizadas, compreendendo-as como produções culturais dinâmicas, diversificadas e contraditórias. (GONZÁLEZ; FRAGA, 2009a, p. 113). 
Na fala acima, o material das LRG explica qual direcionamento deve ser dado à Educação Física no ambiente escolar. Afirma-se que a aptidão física não é mais a principal finalidade da Educação Física. O que cabe ressaltar neste momento é que existem ainda inúmeras outras propostas educacionais para a Educação Física no campo das possibilidades de trabalho do professor. Nesse movimento de troca se excluem as possibilidades de em determinados momentos definir o que é melhor ou pior para um ambiente escolar específico, levando em consideração as relações acerca da história de vida dos sujeitos envolvidos com a comunidade escolar (OLIVEIRA; NEIRA, 2018).

González (2013), corroborando com Fraga (2013), também defende a necessidade de tratar a Educação Física enquanto uma disciplina. Um dos marcos apoiados é a defesa no âmbito escolar da Educação Física com as mesmas condições e atribuições dos demais componentes curriculares, reafirmando determinado modelo e formato de escola moderna, que tem como preceitos a organização, a sistematização e o sequenciamento dos saberes. Para essa identidade de escola, a proposta de cultura corporal de movimento se encaixa nas atribuições do Referencial Curricular do Rio Grande do Sul, haja vista que este continua propondo saberes fragmentados e que não se estabelecem em um conhecimento nas várias dimensões da vida, enquanto um acontecimento datado e provisório, que a qualquer momento pode sofrer uma metamorfose e produzir uma outra forma de pensar a Educação Física.

Nos LRG os conhecimentos mais específicos que são apresentados para Educação Física são os temas estruturadores. Em uma primeira organização, são apresentados os conhecimentos ligados aos conteúdos tradicionalmente reconhecidos pelo campo e denominados pelos autores de práticas corporais, como: esporte, ginástica, jogo motor, lutas, práticas corporais expressivas, práticas corporais junto à natureza e atividades aquáticas. Já o segundo elemento de organização está vinculado ao que os autores chamam de "representações sociais sobre a cultura corporal de movimento", que se dividem em: "práticas corporais e sociedade" e "práticas corporais e saúde".

Os temas estruturadores da Educação Física nas LRG têm como uma de suas referências a Praxiologia Motriz, a qual, segundo Fraga (2013), é um elemento que contribuiu para organizar as discussões acerca das práticas corporais no documento. A Praxiologia Motriz é conhecida no meio acadêmico especialmente pelos trabalhos produzidos pelo professor francês Pierre Parlebas (2001). Segundo Oliveira e Ribas (2010) a praxiologia motriz não é uma concepção de ensino dos esportes, tampouco tem pretensão se tornar uma, embora seus instrumentos de análise sejam utilizados para produzir descrições a respeito de temas como as relações internas dos jogos e dos próprios 
esportes. No caso das Lições do Rio Grande, esse saber está vinculado a uma organização do conhecimento das práticas corporais.

Essa referência não muito usual na Educação Física brasileira é a proposta escolhida pelos autores para organizar e dar concretude às competências e aos temas estruturadores, vinculados às práticas corporais, como os saberes a serem ensinados nas escolas. Essa organização tem como característica fixar o significado de cada tema estruturador e definir em qual deles cada conteúdo da cultura corporal de movimento vai se encaixar, demonstram-se, assim, fortes aproximações com um modelo estruturalista de organização dos saberes (SILVA, 1995), que de forma arbitraria produz e classifica significados e ideias acerca de determinado conteúdo, como pode ser observado, por exemplo, na definição de jogos motores como "aqueles cuja movimentação corporal dos participantes é um elemento essencial, e não apenas utilitário, para sua realização" (GONZÁLEZ; FRAGA, 2009b, p. 103). Nesse contexto, é possível refletir que o elemento da cultura corporal de movimento, o jogo, não se constitui a partir de uma perspectiva histórica a qual sujeitos, através de suas relações, experiências, vivenciando aprendizagens e ensinamentos, produziram uma atividade que, substanciada sob determinado olhar e validada sob determinado saber científico, foi classificada enquanto jogo.

Mesmo que a praxiologia motriz não seja uma concepção didático-pedagógica, como descrevem Oliveira e Ribas (2010), em conjunto com as discussões do Movimento Renovador, elas continuam produzindo formas, estruturas, normas que instituem o saber da cultura corporal de movimento como o pedagogicamente adequado para se trabalhar com a disciplina Educação Física dentro das Lições do Rio Grande. Nesse sentido a praxiologia motriz acaba reforçando a questão da estrutura e da norma, organizando o saber da Educação Física.

A caracterização de Esportes apresentada por Parlebas (1999, p. 197) está submetida à autoridade institucionalmente reconhecida; são regidos por regulamento mais preciso, confiado e reconhecido, profundamente atrelados aos processos socioeconômicos de produção e de consumo - sustentam que o mundo do esporte institucionalizado, chamado por Kunz de Esporte de Rendimento, fomenta princípios de sobrepujança e de comparações objetivas, formas essas que não deverão entrar na escola sem uma transformação pedagógica (OLIVEIRA; RIBAS, 2010, p. 131).

Embora apareça apenas em uma entrevista e nas referências das Lições do Rio Grande, essa forma de 'olhar' permeou toda a organização dos temas estruturadores e guiou, possivelmente, um enfoque maior para o esporte em relação às demais manifestações da CCM, dando aos temas certa hierarquia. 
No documento Lições do Rio Grande, o esporte acaba ganhando grande destaque, sendo entre todos os anos escolares da segunda fase do Ensino Fundamental e por todo o Ensino Médio a temática com maior valoração, ou pelo menos a temática que ganha o direito de desfrutar do maior tempo disponível para as suas atividades. Entre a 5ạ série do Ensino Fundamental e o 30 ano do Ensino Médio, de 40\% a 50\% do tempo disponível para as atividades da disciplina Educação Física, devem ser destinados à abordagem dessa temática. E nesse cálculo ainda não estão computadas todas as atividades que de alguma forma se relacionam com a discussão esportiva e/ou do esporte, como o trato esportivo da ginástica, das lutas, das atividades aquáticas.

Na sequência das prioridades a serem trabalhadas no ambiente escolar, ganha destaque a ginástica, seguida pela ordem por: práticas corporais expressivas; práticas corporais e saúde; práticas corporais e sociedade; atividades aquáticas; jogo motor; e, por último, as lutas. Nesse formato de organização, esporte, ginástica, práticas corporativas expressivas, práticas corporais e saúde, práticas corporais e sociedade devem ser desenvolvidos em todas as fases do Ensino Fundamental e Médio. Já os temas das práticas corporais junto à natureza aparecem em cinco períodos, da 7ạ série do Ensino Fundamental até o 3o ano do Ensino Médio. As atividades aquáticas em três fases estão colocadas da 7ạ série até o 1ํano do Ensino Médio. O jogo motor e as lutas em duas fases: o primeiro na 5a e 6a séries, e o segundo na 7a e 8a séries. Esse modelo de organização é produtora de subjetividades, visto que integra uma forma disciplinar no trato com a Educação Física:

A disciplina 'fabrica' indivíduos; ela é a técnica específica de um poder que toma os indivíduos ao mesmo tempo como objetos e como instrumentos de seu exercício. Não é um poder triunfante que, a partir de seu próprio excesso, pode-se fiar em seu super poderio; é um poder modesto, desconfiado, que funciona a modo de uma economia calculada, mas permanente (FOUCAULT, 1993, p. 153).

Ao olhar para o LRG, cabe perguntar-se "como foram valorados/escolhidos os saberes a serem desenvolvidos na disciplina Educação Física escolar"? Ou ainda, "por que o espaço de uma temática se sobrepõe ao de outra"? A respeito dessas interrogações, os organizadores do documento argumentam que:

Então, a gente escolheu para o segundo ciclo dos anos finais, para o Ensino Médio, para o primeiro ano - ciclo 1 do Ensino Médio - e segundo e terceiro - ciclo 2 -, trabalhar com o tema esporte, porque é sabido que é o conteúdo mais presente na escola (GONZÁLEZ, 2013, p. 12).

[...] A escolha do esporte se deve ao fato de que é um elemento central dos trabalhos da Educação Física na escola. [...] A gente pensou que seria importante trabalhar com algo que é tido como um elemento muito marcante na cultura 
escolar, e que julgamos realmente importante ser trabalhado dentro da perspectiva traçada no referencial para mostrar que existem outras dimensões do esporte que não podem ser trabalhadas (FRAGA, 2013, p. 15).

Essa distribuição reflete, de certa forma, a construção histórica da área, que colocou o esporte como destaque e, por vezes, como sinônimo da Educação Física. Mesmo assim, merece ser questionada. Toda essa organização e sistematização das temáticas a serem trabalhadas nas Lições do Rio Grande, com os seus seguintes percentuais e valoração de prioridades, remete a uma ideia moderna de escola, em que se faz necessário formatar e delimitar o que, como e quando devem ser abordados os saberes de cada área do conhecimento.

Como é possível perceber no excerto acima, o esporte vem sendo conteúdo privilegiado da Educação Física há várias décadas. Segundo a proposta curricular para as escolas estaduais do Rio do Sul, deve continuar a ser, contudo, abordado de maneira diferente das já trabalhadas anteriormente, como aptidão física, detecção de talentos, entretenimento. É preciso refletir sobre a possibilidade de que esse maior espaço dado ao esporte pode funcionar tanto como uma forma de questionar as formas hegemônicas como uma forma de reforçá-las.

Entendemos que em um documento que busque fixar o referencial curricular de um estado da federação, os autores ficam na 'corda bamba' das definições e, por vezes, optam por determinado saber em detrimento de outro, e que dificilmente se agradará a todos. Mas em um documento que se propõe a seguir a perspectiva teórico-prática do Movimento Renovador, dando ao professor um papel de protagonista no processo ensino-aprendizagem, a definição de percentuais ainda nos parece ser contraditória à própria lógica defendida na elaboração do material, quando se afirma como um guia de estudos e possibilidades. Dessa forma, compreendemos que a diversidade das práticas corporais existe de fato no documento, contudo elas não são valorizadas com base nas histórias de vida dos sujeitos envolvidos no processo escolar, enquadrando, assim, os saberes da Educação Física em um formato.

\section{CONSIDERAÇÕES FINAIS}

Ao largo do artigo foram problematizadas determinadas verdades 'pedagógicas' que sistematizam, sequenciam, esquadrinham e privilegiam determinados saberes e conhecimentos do componente curricular Educação Física nas Lições do Rio Grande. Os documentos das LRG demonstraram estar imersos nos interesses de uma escola moderna, daquela que não vem privilegiando a história, os anseios, significados, as invenções dos professores e alunos em seu dia a 
dia, contrariando parte das formulações de autores ligados à formação de professores que buscam valorizar a cultura docente (TARDIF, 2002; GAUTIER et al., 1998).

No caso das Lições do Rio Grande, ainda é possível observar dois elementos que parecem ser o cerne de sua constituição. O primeiro está relacionado ao grupo político que estava à frente das ações governamentais do estado do Rio Grande do Sul e devido a isso, eram responsáveis por propor as políticas públicas, o PSDB. Tal partido direcionou como elementos centrais para este referencial uma série de características que, ao longo dos últimos anos, marcaram as suas ações políticas, como a ideia das competências, em especial as competências de ler, escrever e resolver problemas.

O currículo por competências, articulado à permanência do currículo disciplinar, compõe um discurso regulador capaz de direcionar o processo de recontextualização do discurso instrucional e produzir o discurso pedagógico. Em outras palavras, permanece a organização disciplinar, mas nesse caso os conteúdos mostram-se submetidos às exigências das competências a serem formadas.

É preciso considerar que tais orientações oficiais não foram assimiladas pelas instituições educacionais da mesma maneira. Uma vez estabelecidas as diretrizes curriculares oficiais, elas produzem efeitos nas escolas e demais instituições educacionais, no entanto a incorporação efetiva ao currículo em ação nas mesmas não ocorre sem resistências e processos de recontextualização capazes de produzirem outras organizações curriculares (LIMA; ALMEIDA, 2019; RODRIGUES; DARIDO, 2011).

Segundo as análises realizadas, o Referencial Curricular do Rio Grande do Sul utiliza-se de uma determinada discursividade (FOUCAULT, 2008) acerca do saber da cultura corporal de movimento, para justificar o privilégio do conteúdo esporte em detrimento dos demais. Essa seleção ou privilégio não partiu de interesses advindos das instituições escolares, visto a não realização de consultas ou pesquisas realizadas previamente junto às comunidades escolares para levantar quais saberes da Educação Física seriam importantes para determinada escola.

A forma como é proposta a sequência e divisão (esquadrinhamento) dos saberes da Educação Física escolar acaba por deixar pouco espaço para os momentos de criação de professores e alunos. Dificulta-se, sobretudo, a produção dos sujeitos na prática pedagógica, facilitando mais uma vez a reprodução e o desenvolvimento de temas, fixos, formatados, em uma espécie de caixa, com vários cadeados, o que dificulta muito a sua abertura, modificação, (re)configuração, com os elementos que produzam outros sentidos, significados e significantes, nas relações desses sujeitos (CORAZZA, 2001). 
Dessa maneira deixamos algumas temáticas a serem investigadas em futuras pesquisas sobre currículo: condições estruturais de aplicação dos referenciais (capacitações realizadas, o uso do documento pelos professores da rede, entre outros), formação continuada dos professores da rede após o documento, estrutura das escolas para aplicação do documento, formas de apropriação de um documento curricular, condições de trabalho dos professores, espaços e equipamentos para a Educação Física no estado, relação com outros documentos curriculares contemporâneos, legitimidade dos conteúdos da Educação Física nas escolas.

\section{REFERÊNCIAS}

ALVARENGA, Luiz Fernando Calage. "Flores de plástico não morrem"? Educação, Saúde e Envelhecimento na perspectiva de Gênero. Dissertação (Mestrado em Educação) - Programa de Pós-Graduação em Educação, Faculdade de Educação, Universidade Federal do Rio Grande do Sul, 2006.

AMARAL, Josiane Carolina Soares Ramos do. A política de gestão da educação básica na rede estadual de ensino do Rio Grande do Sul (2007-2010): o fortalecimento da gestão-gerencial. Tese (Doutorado em Educação) - Programa de Pós-Graduação em Educação, Faculdade de Educação, Universidade Federal do Rio Grande do Sul, Porto Alegre, 2010.

BAUMAN, Zygmunt. Identidade: entrevista a Benedetto Vechi. Rio de Janeiro: Jorge Zahar, 2005.

BRACHT, Valter. Educação Física e ciência: cenas de um casamento (in)feliz. ljuí: Ed. Unijuí, 1999.

BRASIL. Senado Federal. Lei de Diretrizes e Bases da Educação Nacional, no 9.394/1996. Brasília: Senado Federal, 1996.

BRASIL. Ministério da Educação e Cultura. Secretaria de Educação Fundamental. Parâmetros Curriculares Nacionais. Brasília: MEC/SEF, 1997.

CAPARROZ, Francisco Eduardo. Entre a Educação Física na escola e a Educação Física da escola: a Educação Física como componente curricular. Campinas: Autores Associados, 2005.

CORAZZA, Sandra Mara. O que quer um currículo? Pesquisas pós-críticas em educação. Petrópolis: Vozes, 2001.

CORAZZA, Sandra Mara. Diferença pura de um pós-currículo. In: LOPES, Alice C.; MACEDO, Elizabeth. (org.). Currículo: debates contemporâneos. São Paulo: Cortez, 2002. p. 103-114.

COUTINHO, Karyne Dias; SOMMER, Luis Henrique. Discursos sobre formação de professores e arte de governar. Currículo sem Fronteiras, v. 11, n. 1, p. 86-103, 2011.

FARENZENA, Nalú. A emenda da obrigatoriedade: mudanças e permanências. Revista Retratos da Escola, Brasília, v. 4, n. 7, p. 197-209, jul./dez. 2010. 
FOUCAULT, Michel. Vigiar e punir: nascimento da prisão. Petrópolis: Vozes, 1993.

FOUCAULT, M. Arqueologia do saber. Rio de Janeiro: Forense Universitária, 2008.

FRAGA, Alex Branco. Depoimento de Alex Branco Fraga: Projeto Garimpando Memórias. Porto Alegre: Centro de Memória do Esporte - Esef/UFRGS, 2013.

GAUTHIER, Clermont et al. Por uma teoria da Pedagogia. Ijuí: Ed. Unijuí, 1998.

GONZÁLEZ, Fernando Jaime; FRAGA, Alex Branco. Referencial Curricular de Educação Física. In: RIO GRANDE DO SUL. Secretaria de Estado da Educação. Departamento Pedagógico (org.).

Referenciais Curriculares do Estado do Rio Grande do Sul - Lições do Rio Grande: Linguagens, Códigos e suas Tecnologias. Porto Alegre: Secretaria de Estado da Educação do Rio Grande do Sul, 2009a, v. II. p. 113-181.

GONZÁLEZ, Fernando Jaime; FRAGA, Alex Branco. Educação Física - Ensino Fundamental: Caderno do Professor. In: RIO GRANDE DO SUL. Secretaria de Estado da Educação. Departamento Pedagógico (org.). Referenciais Curriculares do Estado do Rio Grande do Sul - Lições do Rio Grande: Linguagens, Códigos e suas Tecnologias - Arte e Educação Física - Caderno do Professor. Porto Alegre: Secretaria de Estado da Educação do Rio Grande do Sul, 2009b, v. 2. p. 97-130.

GONZÁLEZ, Fernando Jaime. Depoimento de Fernando Jaime González: Projeto Garimpando Memórias. Porto Alegre: Centro de Memória do Esporte - Esef/UFRGS, 2013.

HALL, Stuart. A identidade cultural na pós-modernidade. Rio de Janeiro: DP\&A, 2002.

LIMA, Amarilton César Nascimento; ALMEIDA, Felipe Quintão de. Apropriações curriculares na rede municipal de Serra/ES. Revista Tempos e Espaços em Educação, São Cristovão, v. 12, n. 28, p. 307-322, 2019.

NEIRA, Marcos Garcia. Teorias pós-críticas da educação: subsídios para o debate curricular da Educação Física. Dialogia, São Paulo, v. 02, n. 14, p. 195-206, 2011.

OLIVEIRA, Glaurea Nádia Borges de; NEIRA, Marcos Garcia. Currículo, educação física e hibridismo: um olhar sobre as orientações curriculares para o ensino fundamental do estado da Bahia. Revista Tempos e Espaços em Educação, São Cristovão, v. 11, n. 26, p. 323-338, 28, 2018.

OLIVEIRA, Gil Teixeira; RIBAS, João Francisco Magno. Articulações da praxiologia motriz com a Concepção Crítico-Emancipatória. Movimento, Porto Alegre, v. 16, n. 1, p. 131-148, 2010.

PARLEBAS, Pierre. Juegos, deporte y sociedad: léxico de praxiología motriz. Barcelona: Paidotribo, 2001.

RENOVATO, Rogério Dias et al. Significados e sentidos de saúde socializados por artefatos culturais: leituras das imagens de advertência nos maços de cigarro. Ciência \& Saúde Coletiva [online], v. 14, supl. 1, p. 1599-1608, 2009. 
RIO GRANDE DO SUL. Secretaria de Estado da Educação. Departamento Pedagógico (org.).

Referencial Curricular do Rio Grande do Sul - Lições do Rio Grande: Linguagens, Códigos e suas Tecnologias - Artes e Educação Física. Porto Alegre: Secretaria de Estado da Educação do Rio Grande do Sul, 2009, v. 2.

RODRIGUES, Heitor de A.; DARIDO, Suraya C. O livro didático na educação física escolar: a visão dos professores. Motriz, Rio Claro, v. 17, n. 1, p. 48-61, 2011.

SILVA, Bruno de Oliveira e. Lições do Rio Grande: "a boa pedagogia" nos discursos sobre a produção de um currículo para a Educação Física escolar. Dissertação (Mestrado em Educação em Ciências) Programa de Pós-Graduação em Educação em Ciências: Químicas da Vida e Saúde, Universidade Federal do Rio Grande, 2014.

SILVA, Tomaz Tadeu da. $O$ adeus às metanarrativas. In: SILVA, Tomaz Tadeu da (org.). $\mathbf{O}$ sujeito da educação: estudos foucaultianos. Petrópolis: Vozes, 1994. p. 247-258.

SILVA, Tomaz Tadeu da. O projeto educacional moderno: identidade terminal? In: VEIGA-NETO, Alfredo (org.). Crítica pós-estruturalista e educação. Porto Alegre: Sulina, 1995. p. 245-261.

SILVA, Tomaz Tadeu da. Documentos de identidade: uma introdução às teorias do currículo. Belo Horizonte: Autêntica, 2011.

SOARES, Carmem Lúcia. Educação Física: raízes europeias e Brasil. Campinas: Autores Associados, 1994.

SOUZA JÚNIOR, Marcílio B. M. et al. Educação física e livro didático: entre o hiato e o despertar.

Movimento, Porto Alegre, v. 21, n. 2., p. 479-493, abr./jun. 2015.

TARDIF, Maurice. Saberes docentes e formação profissional. Petrópolis: Vozes, 2002.

TRINDADE, Iole Maria Favieiro. Uma análise cultural de discursos sobre alfabetização e alfabetismo/letramento e suas representações. Educação, Santa Maria, v. 32, n. 1, p. 41-58, 2007.

\section{SOBRE OS AUTORES}

\section{Bruno de Oliveira e Silva}

Doutorando, UFES; Universidade Federal do Espírito Santo - Brasil; Programa de Pós-Graduação em Educação Física; Laboratório de Estudos em Educação Física - LESEF.

E-mail: brunooliveira2306@gmail.com

ORCID: https://orcid.org/0000-0002-1729-651X

\section{Leonardo Trápaga Abib}

Doutor, UFES; Universidade Federal do Espírito Santo - Brasil; Laboratório de Estudos em Educação Física LESEF.

E-mail: leoabib@gmail.com

ORCID: https://orcid.org/0000-0001-9335-2141 
José Geraldo Soares Damico

Doutor, UFRGS; Universidade Federal do Rio Grande do Sul - Brasil; Docente do Programa de Pós-Graduação em Psicanálise: Clínica e Cultura; Grupo de pesquisa Egbe: Negritude, clínica e comum.

E-mail: zdamico@yahoo.com.br

ORCID: https://orcid.org/0000-0002-6111-1762

Recebido em: 10/07/2020

Aprovado em: 22/09/2020

Publicado em: 07/10/2020 